\title{
Tigecycline: pharmacological concerns and resistance
}

\author{
Rama Paudel $^{1 *}$, Hari P. Nepal ${ }^{2}$
}

\begin{abstract}
${ }^{1}$ School of Biomedical Sciences, ${ }^{2}$ School of Medicine, Trinity Medical Sciences University, Kingstown, St. Vincent and the Grenadines, West Indies
\end{abstract}

Received: 15 June 2020

Accepted: 10 July 2020

*Correspondence:

Dr. Rama Paudel,

Email: paudelrama2015@gmail.com

Copyright: $(\mathcal{C}$ the author(s), publisher and licensee Medip Academy. This is an open-access article distributed under the terms of the Creative Commons Attribution Non-Commercial License, which permits unrestricted non-commercial use, distribution, and reproduction in any medium, provided the original work is properly cited.

\begin{abstract}
Tigecycline, a semisynthetic derivative of minocycline, has a broad spectrum of activity against both gram positive and gram negative multidrug resistant bacteria. The drug acts on $30 \mathrm{~S}$ ribosomal subunit and inhibits protein synthesis. Since the drug has excellent tissue distribution, it is very useful for treatment of skin infections, intraabdominal infections and pneumonia. Side effects of the drug are usually mild. The common side effects include nausea and vomiting. The exact mechanism of resistance remains unclear. However, resistance mediated by enhanced expression of resistance nodulation cell division (RND) type efflux pumps is one of the most frequently reported mechanisms. Resistance has been observed worldwide. However, the rate of resistance is low.
\end{abstract}

Keywords: Tigecycline, Multidrug resistant bacteria, Resistance

\section{INTRODUCTION}

Tigecycline is the first drug in the glycylcycline class of antibiotics to be approved. ${ }^{1}$ It is semisynthetic derivative of minocycline, a tetracycline antibiotic. ${ }^{1}$ It overcomes the two major mechanisms of tetracycline resistance: tetracycline specific efflux pump acquisition and ribosomal protection. ${ }^{2}$ It exhibits broad-spectrum activity against both gram positive and gram-negative bacteria, including many multidrug resistant pathogens. ${ }^{3,4}$ Tigecycline is considered as a drug of last resort against infections caused carbapenem-resistant gram-negative bacteria. $^{5}$

Tigecycline was approved by the US food and drug administration (FDA) in 2005 and by the European Medicines Agency (EMEA) in 2006 for the treatment of complicated skin structure infections (cSSSIs) and complicated intra-abdominal infections (cIAIs) in adults. ${ }^{6}$ The drug further received an approval in March 2009 from FDA for the treatment of community acquired pneumonia (CAP) caused by Streptococcus pneumoniae (penicillin-susceptible isolates), including cases with concurrent bacteremia, Haemophilus influenzae (beta lactamase negative isolates) and Legionella pneumophila. ${ }^{7}$

The purpose of this article is to review important pharmacological characteristics of tigecycline and its resistance.

A search of the literature was made using medline database, google database and online journals. The search was limited to publications in the English language. The search terms 'tigecycline', 'pharmacology of tigecycline' or 'tigecycline resistance' were used. Additional information was obtained from standard book and the website of Medscape.

\section{MECHANISM OF ACTION}

Tigecycline enters the bacterial cell by active transport or passive diffusion and, similar to tetracyclines, binds reversibly to the $30 \mathrm{~S}$ ribosomal subunit preventing 
peptide elongation and inhibiting synthesis of bacterial proteins. ${ }^{8}$

The enhanced binding affinity and antibacterial potency of this drug compared to other tetracycline antibiotics is attributable to stacking interactions between the unique 9 t-butylglycylamido group of tigecycline and the $16 \mathrm{~S}$ rRNA of the $30 \mathrm{~S}$ ribosomal subunit. ${ }^{9}$ The bulkiness of this moiety also contributes to circumvent the common mechanisms of tetracycline resistance. ${ }^{9}$

\section{PHARMACOKINETIC EFFECT}

Tigecycline has poor gastrointestinal absorption. ${ }^{1}$ Therefore, it must be administered intravenously. ${ }^{1}$ The drug is given as a $100 \mathrm{mg}$ loading dose, then $50 \mathrm{mg}$ every 12 hours. ${ }^{1}$ Tissue and intracellular penetration of this drug, similar to all tetracyclines, is excellent and the volume of distribution is quite large. ${ }^{1}$ Therefore, it will be most useful as empirical therapy for polymicrobial infections, especially in cases in which deep tissue penetration is needed or in which multidrug-resistant pathogens are suspected. ${ }^{2}$

However, it has low peak plasma concentrations of $0.8-1$ $\mathrm{mg} / \mathrm{l}$, which is discouraging for treatment of bacteremia due to micro-organisms with an MIC $\geq 1 \mathrm{mg} / \mathrm{l}$ and may be associated with possible poor clinical outcome and the emergence of tigecycline-resistant organisms. ${ }^{10}$

Tigecycline does not interfere with common cytochrome P450 enzymes, thus, pharmacokinetic drug interactions are uncommon. ${ }^{2}$

The drug is eliminated primarily via biliary excretion. No dosage adjustment is required for patients with renal insufficiencies. ${ }^{1}$

About $15 \%$ of tigecycline is excreted unchanged in the urine under standard dosing, which is not encouraging for successful treatment of urinary tract infection (UTI). ${ }^{11} \mathrm{~A}$ previous study has indicated that administration of this drug for UTIs was associated with low microbiological treatment rate and a high rate of isolation of tigecycline non-susceptible isolates. ${ }^{12}$ However, various studies have reported successful outcomes with tigecycline therapy in patients with a UTI. ${ }^{13,14}$

\section{INDICATIONS}

The following are the recommended indications of tigecycline. ${ }^{15}$ Complicated skin infections caused by Escherichia coli, Enterococcus faecalis (vancomycinsusceptible only), Staphylococcus aureus (MRSA and methicillin-susceptible), Streptococcus pyogenes, Streptococcus anginosus group, Streptococcus agalactiae, or Bacteroides fragilis. Complicated intraabdominal infections caused by Escherichia coli, Enterococcus faecalis (vancomycin-susceptible only), $S$. aureus (methicillin-susceptible only), Citrobacter freundii, Enterobacter cloacae, Klebsiella pneumoniae, $K$. oxytoca, B. thetaiotaomicron, B. uniformis, $B$. vulgatus, Clostridium perfringens, Peptostreptococcus micros. Community-acquired pneumonia caused by Streptococcus pneumoniae, Haemophilus influenzae, and Legionella pneumophila.

\section{PROMISING RESULTS IN OTHER CONDITIONS}

The drug is also showing promising results in treatment of other conditions such as cancers and malaria. ${ }^{16,17}$ In cancer, it has been found to induce cell cycle arrest, apoptosis, autophagy and oxidative stress and inhibit mitochondrial oxidative phosphorylation, cell proliferation, migration, invasion and angiogenesis. ${ }^{16}$

An in-vitro evaluation study highlighted that the antimalarial activity of tigecycline was significantly higher against chloroquine resistant than against chloroquine susceptible $P$. falciparum strain. This drug also selectively potentiated the anti-malarial action of chloroquine against chloroquine resistant $P$. falciparum strain. $^{17}$

\section{ADVERSE DRUG EFFECTS}

The common side effects of tigecycline include nausea and vomiting. Cumulative incidences of nausea and vomiting in over 13 trials were about $26 \%$ and $18 \%$ respectively. ${ }^{11}$ The exact mechanism for these adverse gastrointestinal events remains unknown. However, they were manageable with the use of standard antiemetic therapies and did not require discontinuation of the drug. ${ }^{11}$

The other side effects reported in $1-15 \%$ the people include diarrhea, infections, fever, abdominal pain, headache, hypertension, hypotension, anemia, dizziness, dyspnea, pruritus, rash and insomnia. ${ }^{15}$

\section{BOXED WARNING}

Based on meta-analyses of 10 clinical trials, a boxed warning was issued by FDA in 2010 since the drug was found to be associated with an increased risk of death. ${ }^{18}$ Higher mortality associated with this drug was also reported by other studies. ${ }^{19,20}$

\section{RESISTANCE}

Resistance against tigecycline has emerged worldwide since its approval. ${ }^{21}$

\section{Mechanism of resistance}

The exact mechanism of resistance to tigecycline has not yet been clearly elucidated. ${ }^{21}$ Enhanced expression of resistance nodulation cell division (RND) type efflux pumps in gram-negative bacteria was associated with decreased tigecycline susceptibility. ${ }^{22}$ Over-expression of 
the RND efflux pumps, AcrAB and OqxAB, is one of most frequently reported mechanisms in the Enterobacteriaceae members. Several global transcriptional regulators of the AraC family, namely, RamA, MarA, SoxS, and RarA have been found to contribute to tigecycline resistance via efflux pump activation. ${ }^{23-26}$ A new efflux pump operon, kpgABC mediated resistance was reported by Nielsen et al in $K$. pneumoniae. ${ }^{27}$ Alteration of ribosomal binding site via mutation has also been described for its ability to cause decreased tigecycline susceptibility in both gram negative and gram positive bacteria. ${ }^{28,29}$

\section{Epidemiology of resistance}

Variable rates of resistance have been observed worldwide in various bacterial pathogens including Acinetobacter spp., Pseudomonas spp. and Enterobacteriaceae family members such as Escherichia coli, Enterobacter spp., Klebsiella spp. and Serratia spp. ${ }^{8,11}$ The drug is found to retain low non-susceptibility rates of $<10 \%$ among Enterobacteriaceae members worldwide in most large-scale surveillance studies. ${ }^{30-33}$ However, higher rate of resistance has been observed among extended-spectrum $\beta$-lactamase (ESBL) producing, multidrug resistant (MDR), extensively drugresistant and carbapenem resistant (CR) isolates. ${ }^{8}$ In the Americas, many studies have reported resistance rate of $<10 \%{ }^{34-37}$ However, few studies have reported higher rate of resistance. ${ }^{38,39}$

In the Asia-Pacific countries, resistance rate exhibited by the bacterial pathogens including ESBL-producing isolates and ertapenem-resistant E. coli, K. pneumoniae and E. cloacae was $<10 \% .{ }^{40,41}$ However, ertapenemresistant isolates of E. aerogenes and $S$. marcescens had exhibited $31 \%$ and $20 \%$ resistance, respectively. ${ }^{42}$ In Africa and the Middle East, multiple studies have reported non-susceptibility rates of $<10 \% .{ }^{43-45}$ In Europe, large number of studies reported a tigecycline nonsusceptibility rate of $10 \%$ or less among ESBLproducing, carbapenem resistant and multidrug resistant strains. ${ }^{46-48}$

\section{CONCLUSION}

In the era of limited available antimicrobial options, tigecycline is a valuable drug for treatment of serious infections such as complicated skin infections, complicated intra-abdominal infections and communityacquired pneumonia.

Funding: No funding sources Conflict of interest: None declared

Ethical approval: Not required

\section{REFERENCES}

1. Beauduy CE, Winston LG. Chapter 44: Tetracyclines, Macrolides, Clindamycin,
Chloramphenicol, Streptogramins, and Oxazolidinones. In: Katzung BG, editor. Basic and Clinical Pharmacology, 14e. New York, NY: McGraw-Hill; 2018. Available at http://accessmedicine.mhmedical.com/content.aspx?b ookid $=2249 \&$ sectionid $=175215158$. Accessed on 10 May 2020.

2. Stein GE, Craig WA. Tigecycline: A Critical Analysis. Clin Infect Dis. 2006;43:518-24.

3. Sum PE, Petersen P. Synthesis and structure-activity relationship of novel glycylcycline derivatives leading to the discovery of GAR-936. Bioorg Med Chem Lett. 1999;9:1459-62.

4. Petersen PJ, Jacobus NV, Weiss WJ, Sum PE, Testa RT. In vitro and in vivo antibacterial activities of a novel glycylcycline, the 9-t-butylglycylamido derivative of minocycline (GAR-936). Anti-microb Agents Chemother. 1999;43:738-44.

5. Wang Q, Zhang P, Zhao D, Jiang Y, Zhao F, Wang $\mathrm{Y}$, et al. Emergence of tigecycline resistance in Escherichia coli co-producing MCR-1 and NDM-5 during tigecycline salvage treatment. Infect Drug Resist. 2018;11:2241-8.

6. Kasbekar N. Tigecycline: a new glycylcycline antimicrobial agent. Am J Health Syst Pharm. 2006;63:1235-43.

7. Letter to Wyeth Pharmaceuticals, Inc. Department of Health and Human Services; 2009. Available at https://www.accessdata.fda.gov/drugsatfda_docs/appl etter/2009/021821s013,021821s017,021821s0181tr.p df. Accessed on 10 May 2020.

8. Pournaras S, Koumari V, Spanakis N, Gennimata V, Tsakris A. Current perspectives on tigecycline resistance in Enterobacteriaceae: susceptibility testing issues and mechanisms of resistance. Int $\mathbf{J}$ Antimicrob Agents. 2016;48:11-8.

9. Jenner L, Starosta AL, Terry DS, Mikolajka A, Filonava L, Yusupov M, et al. Structural basis for potent inhibitory activity of the antibiotic tigecycline during protein synthesis. Proc Natl Acad Sci. 2013;110(1):3812-6.

10. Seputiene V, Povilonis J, Armalyte J, Suziedelis K, Pavilonis A, Suziedeliene E. Tigecycline how powerful is it in the fight against antibiotic-resistant bacteria. Medicina (Kaunas). 2010;46:240-8.

11. Stein GE, Babinchak T. Tigecycline: an update. Diagn Microbiol Infect Dis. 2013;75:331-6.

12. Satlin MJ, Kubin CJ, Blumenthal JS, Cohen AB, Furuya EY, Wilson SJ, et al. Comparative effectiveness of aminoglycosides, polymyxin B, and tigecycline for clearance of carbapenem-resistant Klebsiella pneumoniae from urine. Anti-microb Agents Chemother. 2011;55:5893-9.

13. Cunha BA, McDermott B, Nausheen S. Single daily high-dose tigecycline therapy of a multidrug-resistant (MDR) Klebsiella pneumoniae and Enterobacter aerogenes nosocomial urinary tract infection. J Chemother. 2007;19:753-4.

14. Geerlings SE, Donselaar VD, Pant KA, Keur I. Successful treatment with tigecycline of two patients 
with complicated urinary tract infections caused by extended-spectrum $\quad \beta$-lactamase-producing Escherichia coli. J Anti-microb Chemother. 2010;65:2048-9.

15. Tigecycline $(\mathrm{Rx}) . \quad$ Available at https://reference.medscape.com/drug/tygacil-tigecycline-342527\#0. Accessed on 10 May 2020.

16. Dong Z, Abbas MN, Kausar S, Yang J, Li L, Tan L, et al. Biological Functions and Molecular mechanisms of antibiotic tigecycline in the treatment of cancers. Int J Mol Sci. 2019;20:3577.

17. Sahu $\mathrm{R}$, Walker LA, Tekwani BL. In vitro and in vivo anti-malarial activity of tigecycline, a glycylcycline antibiotic, in combination with chloroquine. Malaria J. 2014;13:414.

18. US Food and Drug Administration. FDA drug safety communication: FDA warns of increased risk of death with IV antibacterial Tygacil (tigecycline) and approves new boxed warning. Silver Spring (MD): FDA; 2013.

19. Tasina E, Haidich AB, Kokkali S, Arvanitidou M. Efficacy and safety of tigecycline for the treatment of infectious diseases: a meta-analysis. Lancet Infect Dis. 2011;11:834-44.

20. Prasad P, Sun J, Danner RL, Natanson C. Excess deaths associated with tigecycline after approval based on noninferiority trials. Clin Infect Dis. 2012;54:1699-709.

21. Du X, He F, Shi Q, Zhao F, Xu J, Fu Y, et al. The rapid emergence of tigecycline resistance in blakpc-2 harboring Klebsiella pneumoniae, as mediated in vivo by mutation in TET a during tigecycline treatment. Front Microbiol. 2018;9:648.

22. Sekyere OJ, Govinden U, Bester LA, Essack SY. Colistin and tigecycline resistance in carbapenemase producing gram-negative bacteria: emerging resistance mechanisms and detection methods. J Appl Microbiol. 2016;121:601-17.

23. Ruzin A, Immermann FW, Bradford PA. Real-time PCR and statistical analyses of acrAB and ramA expression in clinical isolates of Klebsiella pneumoniae. Anti-microb Agents Chemother. 2008;52:3430-2.

24. Bratu S, Landman D, George A, Salvani J, Quale J. Correlation of the expression of acrB and the regulatory genes marA, soxS and ramA with antimicrobial resistance in clinical isolates of Klebsiella pneumoniae endemic to New York City. J Anti-microb Chemother. 2009;64:278-83.

25. Veleba M, Higgins PG, Gonzalez G, Seifert H, Schneiders T. Characterization of RarA, a novel AraC family multidrug resistance regulator in Klebsiella pneumoniae. Anti-microb Agents Chemother. 2012;56:4450-8.

26. Veleba M, Schneiders T. Tigecycline resistance can occur independently of the ramA gene in Klebsiella pneumoniae. Anti-microb Agents Chemother. 2012;56:4466-7.

27. Nielsen LE, Snesrud EC, Leone OF, Kwak YI, Aviles R, Steele ED, et al. IS5 element integration, a novel mechanism for rapid in vivo emergence of tigecycline nonsusceptibility in Klebsiella pneumoniae. Anti-microb Agents Chemother. 2014;58:6151-6.

28. Cannatelli A, Giani T, D'andrea MM, Pilato DV, Arena F, Conte V, et al. MgrB inactivation is a common mechanism of colistin resistance in KPCproducing Klebsiella pneumoniae of clinical origin. Anti-microb Agents Chemother. 2014;58:5696-703.

29. Beabout K, Hammerstrom TG, Perez AM, Magalhaes BF, Prater AG, Clements TP, et al. The ribosomal S10 protein is a general target for decreased tigecycline susceptibility. Anti-microb Agents Chemother. 2015;59:5561-6.

30. Sader HS, Flamm RK, Jones RN. Tigecycline activity tested against antimicrobial resistant surveillance subsets of clinical bacteria collected worldwide (2011). Diagn Microbiol Infect Dis. 2013;76:217-21.

31. Bertrand X, Dowzicky MJ. Anti-microbial susceptibility among Gram-negative isolates collected from intensive care units in North America, Europe, the Asia-Pacific Rim, Latin America, the Middle East, and Africa between 2004 and 2009 as part of the Tigecycline Evaluation and Surveillance Trial. Clin Ther. 2012;34:124-37.

32. Sader HS, Jones RN, Stilwell MG, Dowzicky MJ, Fritsche TR. Tigecycline activity tested against 26,474 bloodstream infection isolates: a collection from 6 continents. Diagn Microbiol Infect Dis. 2005;52:181-6.

33. Garrison MW, Mutters R, Dowzicky MJ. In vitro activity of tigecycline and comparator agents against a global collection of gram-negative and grampositive organisms: Tigecycline Evaluation and Surveillance Trial 2004 to 2007. Diagn Microbiol Infect Dis. 2009;65:288-99.

34. Canigia FL, Dowzicky MJ. Susceptibility of important Gram-negative pathogens to tigecycline and other antibiotics in Latin America between 2004 and 2010. Ann Clin Microbiol Anti-microb. 2012;11:29.

35. Sader HS, Farrell DJ, Jones RN. Tigecycline activity tested against multidrug resistant Enterobacteriaceae and Acinetobacter spp. isolated in US medical centers (2005-2009). Diagn Microbiol Infect Dis. 2011;69:223-7.

36. Dowzicky MJ, Park CH. Update on antimicrobial susceptibility rates among Gram-negative and Grampositive organisms in the United States: results from the Tigecycline Evaluation and Surveillance Trial (TEST) 2005 to 2007. Clin Ther. 2008;30:2040-50.

37. Wiens LPR, Simner PJ, Forward KR, Tailor F, Adam HJ, Decorby M, et al. Analysis of 3789 in and outpatient Escherichia coli isolates from across Canada results of the CANWARD 2007-2009 study. Diagn Microbiol Infect Dis. 2011;69:314-19.

38. Sader HS, Farrell DJ, Flamm RK, Jones RN. Variation in potency and spectrum of tigecycline activity against bacterial strains from U.S. medical 
centers since its approval for clinical use (2006 to 2012). Anti-microb Agents Chemother. 2014;58:2274-80.

39. Persio DJR, Dowzicky MJ. Regional variations in multidrug resistance among Enterobacteriaceae in the USA and comparative activity of tigecycline, a new glycylcycline anti-microbial. Int J Anti-microb Agents. 2007;29:518-27.

40. Bouchillon SK, Iredell JR, Barkham T, Lee K, Dowzicky MJ. Comparative in vitro activity of tigecycline and other antimicrobials against gramnegative and gram-positive organisms collected from the Asia-Pacific Rim as part of the Tigecycline Evaluation and Surveillance Trial (TEST). Int J Antimicrob Agents. 2009;33:130-6.

41. Chen $\mathrm{YH}, \mathrm{Lu}$ PL, Huang $\mathrm{CH}$, Liao $\mathrm{CH}$, Lu CT, Chuang YC, et al. Trends in the susceptibility of clinically important resistant bacteria to tigecycline: results from the Tigecycline In Vitro Surveillance in Taiwan study, 2006 to 2010. Anti-microb Agents Chemother. 2012;56:1452-7.

42. Hsu MS, Liao CH, Liu CY, Yang CJ, Huang YT, Hsueh PR. In vitro susceptibilities of clinical isolates of ertapenem-non-susceptible Enterobacteriaceae to nemonoxacin, tigecycline, fosfomycin and other antimicrobial agents. Int $\mathbf{J}$ Anti-microb Agents. 2011;37:276-8.

43. Araj GF, Ibrahim GY. Tigecycline in vitro activity against commonly encountered multidrug-resistant Gram-negative pathogens in a Middle Eastern country. Diagn Microbiol Infect Dis. 2008;62:41115.

44. Renteria MI, Biedenbach DJ, Bouchillon SK, Hoban DJ, Raghubir N, Sajben P, et al. In vitro activity of tigecycline against isolates collected from complicated skin and skin structure infections and intra-abdominal infections in Africa and Middle East countries: TEST 2007-2012. Diagn Microbiol Infect Dis. 2014;79:54-9.

45. Zarouni AM, Senok A, Zarooni AN, Nassay AF, Panigrahi D. Extended spectrum $\beta$-lactamaseproducing Enterobacteriaceae: in vitro susceptibility to fosfomycin, nitrofurantoin and tigecycline. Med Princ Pract. 2012;21:543-7.

46. Lauritsen NN, Marchandin H, Dowzicky MJ. Antimicrobial susceptibility of tigecycline and comparators against bacterial isolates collected as part of the TEST study in Europe (2004-2007). Int J Antimicrob Agents. 2009;34:121-30.

47. Balode A, Polic PV, Dowzicky MJ. Anti-microbial susceptibility of Gram negative and Gram-positive bacteria collected from countries in Eastern Europe: results from the Tigecycline Evaluation and Surveillance Trial (T.E.S.T.) 2004-2010. Int J Antimicrob Agents. 2013;41:527-35.

48. Cattoir V, Dowzicky MJ. A longitudinal assessment of antimicrobial susceptibility among important pathogens collected as part of the Tigecycline Evaluation and Surveillance Trial (T.E.S.T.) in France between 2004 and 2012. Anti-microb Resist Infect Control. 2014;3:36.

Cite this article as: Paudel R, Nepal HP. Tigecycline: pharmacological concerns and resistance. Int J Basic Clin Pharmacol 2020;9:1296300. 